\title{
Las fuentes espirituales de la angustia y de la esperanza
}

\section{Xavier Zubiri}

La gran amiand existente entre Xevier Zubiri e Ignecio Ellocurí unsciende la muerte de ambos. Su pensemiento y su accion aiguen impulando a pensur y a saur. Esto explica el que not hayomon decidido a publicar erte intdito de Xavier Zubiri, que ibe acompartado de le aguiente carta de Cermen Cantro:

Este tero de Xevier Zubiri vivin encondido y pertido. Lo encentre hace dos cernana gracias a Ignecio Ellacurn. SL, verdad digo. He pensedo que a cada uno de los dos, por dietinine nezones, y por su amiried perfects, lea guatarie verlo-leerlo-publicado en une revisu de la U.C.A.

Agradezco entratsblemente, que asi gea.

Camen Castro de Zubiri

$25-X-1990$

La angustia es uno de los temas que exceden a mi competencia, pero no por eso deja de ser un punto de reflexión importante sobre todo por el aspecto filosófico que desde hace unos aflos viene revistiendo. A título, pues, de meras reflexiones generales sobre el tema ofrezco a ustedes estas breves lineas.

La angustia, acabo de decirlo, tiene un aspecto filosofico. Ha sido Heidegger quien ha querido hacer ver que la angustia es uno de los temples de ánimo fundamentales de la existencia humana (eine Grundstimmung des menschlichen Daseins). La angustia se constituye para Heidegger por un doble carácter. Por un lado seria un fenómeno de hundimiento de todo terreno o punto de apoyo; sería por otro, no un movimiento de huida sino, justo al revés, una especial quietud que deja al angustiado como clavado y fijo en el vaclo en que queda. Este fenómeno tiene para Heidegger un alcance radical y fundante. El hombre está apoyado en la vida en los entes que le rodean (das Seiende). Su hundimiento total deja patente ante los ojos de aquél la nada de todo ente. Este vacio es en si mismo algo positivo: es el "ser" (das Sein). Sobre el abismo de los entes queda flotando el puro ser. A fuer de tal, la angustia es para Heidegger un fenómeno ontológico, es la patentización del puro ser a diferencia del ente. Esta interpreta- 
ción es por demás problemática. Problemática, en primer lugar, porque no loca a la estructura concreta de la angustia. Problemática, además, porque se mueve, en el fondo, en una petición de principio: si no fuera porque el hombre ha visto o inteligido ya de alguna manera, antes de toda angustia, eso que llamamos ser, el hundimiento del ente arrastraria al hombre mismo o se producirfa cualquier otro fenómeno, pero no una patentización del puro ser. De suerte que es el ser el fundamento de la angustia, esto es, de la patentización de la nada del ente, y no al revés. Esta vertiente filosólica de la angustia ha venido a imponerse en nuestra época con una fuerza de arrastre que no responde a su significación filosófica Desde el punto de vista filosofico, como en otros tiempos fueron el malheur y el malheureux, son hoy la "angustia" y el "angustiado" el punto en que se centra la reflexión intelectual. Pero al igual que en el caso del malhewr su huella filosofica será casi nula. Lo que sucede es que este fenómeno, a mi modo de ver filosoficamente efímero, viene a superponerse a lo que en la humanidad actual es el hecho de la angustia. Con lo cual ambos aspectos del problema, independientes entre si, se apoyan mutuamente por lo menos en la producción literaria. Es menester disociar ambos aspectos de la cuestión, y tratar de enfrentamos con la angustia como una realidad propia.

Como realidad, en su aspecto más externo, la angustia es, si no un fenómeno social en sentido estricto, si, por lo menos, un estado tan generalizado que puede figurar entre las características de nuestro mundo. El coeficiente de inseguridad de la vida actual en sus propias estructuras sociales hace que la vida de todo hombre en su sociedad esté orlada de un carácter de provisionalidad que amenaza con disolver sus más elementales posibilidades. Al fin, y al cabo, la firmeza ha sido cuando menos uno de los móviles para dotar de estructura a la sociedad. Pero no es sólo esto. Porque la inseguridad consecutiva a la provisionalidad no sería de suyo angustia; podría llevar simplemente al infortunio o a la desesperación. La angustia se produce cuando a pesar de aquella inseguridad la sociedad arrebata sin embargo al individuo y le empuja a tener que vivir. Con lo cual el inseguro quiere parecer seguro, aun sabiéndose incapaz de serlo. Es una "imposición" de vida sin nada en que apoyarla con firmeza Es justo la angustia No es ciertamente todo lo que constituye la angustia; por esto es por lo que dije que no es sino el aspecto más externo de ella. Mas este aspecto social nos deja por lo menos orientados hacia lo que es la angustia en sí misma como estado mental de cada individuo en su propia vida espiritual.

Como estado mental de la vida espiritual, lo que se designa con el nombre de angustia no es algo fácilmente definible. Pero tampoco sea tal vez necesario definirlo: es suficiente sefialar los diversos ingredientes que intervienen en la angustia. Ninguno de ellos es exclusivo de ésta; pero todos juntos la constituyen. Ante todo hay en la angustia un momento de intensa "preocupación". Toda vida lleva consigo un momento de preocupación por el futuro, y en cierta medida un momento de inquietud respecto de él. Aquf no se trata simplemente de un futuro 
remoto, sino formalmente de un futuro próximo. En la medida en que la preocupación aumenta y en que se acorta el plazo de la futurición, es decir, en la medida en que el futuro se hace inminente, y tal vez ineludible, y por otro lado en la medida en que la inquietud va alcanzado a la inseguridad, la preocupación va también cambiando de matiz. No es un mero cambio cuantitativo. Por el aumento de proximidad, el futuro, en efecto, va cobrando una forma propia y peculiar. no es algo como "por-venir", sino algo que se "echa encima". La futurición reviste asi un carácter específico: es "opresión". Y al tomarse la inquietud en inseguridad creciente, la preocupación reviste una nueva cualidad: es "ansiedad". No es una agitación, una hiperactividad; todo lo contrario, es una larvada "paralización". Esta sutil mixtura de inminencia, opresión y ansiedad, que nos deja paralizados ante el futuro inmediato, es característica de la anguslia. En este respecto, como estado mental de la vida espiritual, la angustia descubre, o cuando menos sitúa al angustiado en una siwación peculiar: la "impotencia". He aquí el primer momento de la angustia.

Pero sólo el primero. Ya lo apuntaba al referime a la angustia como característica de nuestra época. Esta impotencia, en efecto, no sería propiamente angustia si la impotencia, en cualquiera de sus componentes, no fuera sino eso: mero "no-poder". Por la opresión, por ejemplo, podríamos dejarnos aplastar por lo inevitable; esto no sería una angustia. La impotencia de la angustia juega dento de una dimensión positiva. Es la impotencia en el torrente vilal que no sólo se nos "ofrece", sino que se nos "impone". Como desde hace muchos años vengo diciendo, la vida no es lo que solemnemente enunciaba Shakespeare: ser o no ser. Si así fuera, la vida sería dura, pero simple: bastaría con optar. La vida no es ser o no ser, sino tener que ser. Y esta positiva dimensión del tener que ser es lo que confiere a la impotencia su propio carácter angustioso.

¿Es esto todo? Ciertamente no. Es verdad que a esto es a lo que todos en general llarnamos angustia, sin gran amor de la precisión. Pero en definitiva lodo ello podría darse y ocurrir sin que fuera propiamente angustia. Sería tan sólo una, tal vez la suprema de las tribulaciones. Pero nada más, y angustia no es sólo tribulación. Es que todos esos momentos esenciales a la angustia no constituyen sino un aspecto de ella: el aspecto que da a lo que de una manera genérica pudiéramos llamar las tendencias hunanas. Toda "tendencia" nos dispara a un luturo, es una "tensión". Pero la vida no es sólo tensión. Es también "pre-tensión". En ella no vamos disparados, sino que nos disparamos. Y como lal la vida es la realización o el malogro de unas posibilidades que la realidad de las cosas, de los demás hombres y de sí mismo ofrecen, o que la persona misma descubre y hasta tal vez crea. La realización de estas posibilidades pende de una condición suprema: su aceplación, su apropiación. El hombre, por tanto, no se mueve tan sólo por tendencias que le llevan, sino entre realidades que acepta o descubre como posibilidades de su vida personal. Y este entregamos activa o pasivamente a la realidad en cuanto realidad posibilitante de mi propia realidad, es 
justo lo que a potiori constituye para mí la esencia de la voluntad. A potiori tan sólo, porque no es nada separable de las tendencias. Todo lo contrario, la integridad de eso que llamamos voluntad envuelve intrínsecamente las tendencias mismas. Suelo decir por esto, que la voluntad humana es intrínseca y formalmente, una voluntad tendente. Sin tendencias, la pura voluntad, la voluntariedad, no pasara de ser, en el mejor de los casos, un bello ideal inoperante; pero sin voluntariedad propiamente dicha las tendencias harian del hombre tan sollo el supremo de los seres sensilivos. El momento de voluntariedad propianente dicho consiste en la apropiación de posibilidades. Y a esto es a lo que temáticamente llamo yo "moral". Moral no es sólo, ni en primera línea, la ética de las acciones conformes o disconformes con un bien moral. Antes que eso moral es el carácter de una realidad, la realidad humana, carácter por el cual ésta tiene algunas propiedades tan sólo por apropiación de posibilidades. Así decimos de un deportista que está o no desmoralizado, indicando con ello simplemente que no está en buena forma, esto es, que no se ha incorporado las posibilidades que hacen de él la realidad de un deportista. Sólo porque el hombre es realidad moral, en este sentido primario, puede ser y es sujeto de esa ordenación de posibilidades que constituyen el bien moral y la ética. El bien moral es pura y simplemente el bien de lo moral en que el hombre consiste. Esto supuesto, la angustia que hemos descrito hasta ahora en términos meramente tendenciales no constituye sino un momento de la angustia estricta. La angustia no es un fenomeno de meras tendencias, es formalmente un fenómeno de voluntad, de voluntariedad tendente. Esto es, sin impotencia y sin estar arrastrados por el tener que vivir, no habria angustia; pero lo que con ello hay no seria sin más angustia. La verdadera y honda angustia envuelve algo más: es sentimos impotentes en el tener que vivir habiendo perdido el sentido de las posibilidades apropiadas por el hombre, habiendo perdido el sentido de su propia realidad: la angustia es una primaria y radical desmoralización. Sin ella no pasaría de ser, como apuntaba antes, una tribulación. Y no hay la menor duda de que la raíz honda de la angustia contemporánea está en el vacío de posibilidades reales, en la profunda desmoralización (en la acepción precisa que he dado a este témino) del hombre actual. No es solo la inseguridad, la opresión, la ansiedad, to ineludible del tener que vivir, es todo esto pero con falta de asidero en el orden de la realidad en cuanto tal como posibilidad de mi vida.

La distición es clara Cuando Cristo se dirigió a Gethsemaní dijo a los apóstoles: "En el mundo teneis opresiones (thlpsin éxete) pero confiad, yo he vencido al mundo". Esta confiada esperanza es lo que eviló que en los apostoles la opresión se convirtiera en estricta angustia. No fue una abolición del sentido de la realidad y de la vida, ni fue una desmoralización. Todo lo contrario; fue en su hora el secreto motor de su vida. No pasó de ser una gran tribulación. Y el propio Cristo, atribulado, oprimido, y hundido por la inminencia de su pasión, no cayó en angustia; se sintió mortalmente triste y abatido, pero le basto con acep- 
tar la voluntad de su Padre, esto es, con asirse al sentido de su vida terrena y a la realidad de su persona divina. Sólo los hombres caemos en angustia, o por lo menos sólo los hombres pueden caer en ella.

En definitiva, la angustia es el sentido de la vida como problema vivido en la impotencia y en el desmayo de los resortes tendenciales que nos fuerzan a vivir. Por bajo de la opresión, de la ansiedad, por bajo de la impotencia en que nos vemos forzados a vivir ante lo incierto del momento, est́n la desorientación, el gemido, y la inquietud de la desmoralización, la pérdida del sentido de la realidad. Lo más angustioso de la angustia es justamente su ausencia de razón de ser. La angustia no patentiza el ser, sino que deja a los entes sin sentido para nuestra existencia

De aqui que la angustia pueda tener origenes muy diversos en nuestra vida espiritual. Por un lado, el momento tendencial de la angustia no puede ser subestimado. Todo lo contrario. Desde las alteraciones puramente fisiológicas hasta los sucesos biográficos individuales o sociales, pasando por las estructuras psicológicas, todo, y en forma muy seria, puede desencadenar la angustia estrict2. Al fin y al cabo, la voluntad desfallece y se desmoraliza ordinariamente cuando fallan o se incoordinan las dimensiones tendenciales que intrínsecamente le pertenecen. La dis-regulación de las tendencias puede deformar moralmente la voluntad. Pero por otro lado, la desmoralización en sí misma puede engendrar angustia, por ejemplo, por la vía de la depresión y de la indiferencia Sin enbargo, mantengamos siempre la unidad de los dos momentos en el fenómeno de la angustia. La angustia es siempre y sólo un fenómeno de voluntad tendente. El animal no puede estar angustiado. Probablemente ningún ángel lo estuvo tampoco.

La angustia es el gran peligro del hombre actual. No es fuente de progreso; todo lo contrario. Es en todos sus aspectos y dimensiones el paralizador de la vida. De ahl que la agudeza y extensión del fenómeno de la angustia humana sea uno de los más graves y sutiles males de nuestra época. No posee ese rango excepcional que ciertas filosofias pretenden otorgarle. Oprimido por la realidad y perdido en ella, el hombre intenta a veces dar el sutil rodeo de complacerse en la angustia. Es tan sólo el supremo espejismo de la inteligencia. Espejismo fue ya hacer de la realidad de la naturaleza y de la historia, la realidad suprema. Pero cuando menos, era "realidad". Ahora, en cambio, se quiere hacer de la angustia y de la opresión del hombre por la realidad, la realidad suprema, mejor dicho, se hace de la "nada" lo supremo del universo y de la vida. Ciertamente en sentido meramente ontológico para Heidegger, cosa que en definitiva nada tiene que ver con el nihilismo. Pero en sentido estricto y de nihilismo moral en el existencialismo. Y esto no es sólo que no sea verdad, es que es flsicamente insostenible.

Y justamente es este, tal vez, el último momento de la angustia integral: su 
estricta insostenibilidad. El angustiado, más que ninguno, vuelve los ojos hacia los demás. Como insostenible, la angusua es una negación de sl misma: nos remite a la realidad en la que estamos angustiados, incluso cuando el hombre la acepta complacido. Por esto la angustia no es sólo un estado: es también y a una un problema, si se quiere un problema como estado. Como tal, la insostenibilidad de la angustia, esto es, la angustia es ya ella en sí misma la marcha incoada hacia la solución del problema. Sólo la marcha; la solución está muy lejos. Precisamente porque la angustia es el problema del sentido de la realidad, vivido en la impotencia de tener que vivir, su solución no puede consistir sino en la reconquista del sentido de la realidad vivida en la regulación de las tendencias vitales. Es quimérico pensar que esta solución pudiera ser solamente ideológica; sería creer que la angustia es un fenómeno de simple derrumbamiento de convicciones morales. Y no es esto; envuelve también intrínsecamente y formalmente la dimensión tendencial. De ahí que la solución de la angustia como problema implica todos los factores que juegan en la estructura tendencial psicobiológica del hombre. Una regulación por higiene no solo física sino también fisiológica; no pueden despreciarse los tratamientos bioquímicos en ningún problema que afecta hondamente a la realidad humana. Una regulación tambien psicológica, en forma de psicolerapia u otras. Una higiene, además, de la vida personal. El hombre actual huye de si mismo y para lograrlo, queriéndolo o sin quererlo, o incluso tal vez queriendo todo lo contrario, ha cultivado un régimen de aturdimiento. La radio, la televisión, el cine, el pik-up, al margen de su utilidad en lodos los órdenes, han pasado a convertirse en instrumentos de aturdimiento. El hombre de hoy necesita entre otras cosas la higiene de la tranquilidad. Necesita también la higiene de la fruición. Parece que el hombre actual se halla en tal forma disparado hacia el futuro que carece de tiempo y de holgura para saber donde tiene apoyados sus pies; no tiene fruiciones, sino perpetuos proyectos en que se devora a sí mismo. El futurismo reacciona sobre el presente disolviéndolo en angustia. El hombre necesita además un mínimo de estabilidad social, jurídica y nacional. Pero esto no es lodo. El hombre necesita ir reconquistando el sentido de la realidad, esto es, recobrar íntimamente su moralización. $Y$ esto no se lograra sin la reconquista de convicciones morales profundas. Ello no eliminara el aspecto aflictivo de la angustia; pero el mero hecho de darle sentido le redimirá de tribulaciones, e impedira que la angustia nos disuelva. ¿Y cómo desconocer que la raíz última de la estabilidad es nuestra vinculación a la ultimidad de lo real como posibilidad de nuestra vida, esto es, lo que hace mucho llamé "religación"? La religación lleva a la religión como la moralización lleva a una ética.

En el sombrio cuadro de la angustia actual hay destellos de desangustización; no proceden de un frívolo optimismo, sino que son síntomas auténticos de recuperación. No puede negarse que por bajo de la inquietud actual, el hombre va sintiendo una saludable fatiga que le empuja a estar cada vez más en sf́ 
mismo, no en un sí mismo monacal, sino en el sí mismo de los suyos. No puede negarse tampoco que a través de tantas alteraciones sociales va adoptando figura cada vez más estable un régimen de mínima seguridad económica. No puede negarse finalmente que bajo las crisis extemas de muchas estrucluras religiosas me reliero al catolicismo- asistimos a una renovación de vidas vividas en profundidad católica, calladas casi siempre, pero a veces más eficaces precisamente por su silencio. Y, ८por qué no decirlo?, en última instancia uno de los tristes fundamentos de esperanza es justo la índole inestable de la angustia misma. Tal vez habrá que apurar más la experiencia. Y llegado el hombre al límite de la angustia despertará un día como de un suefio, y comenzará a ver que en su angustia misma no ha hecho sino estar en la realidad y en Dios. La angustia última serfa tal vez el primer estadio de la recuperación. Sólo Dios sabe lo que en su providencia ha establecido, y lo que en ella ha permitido. 